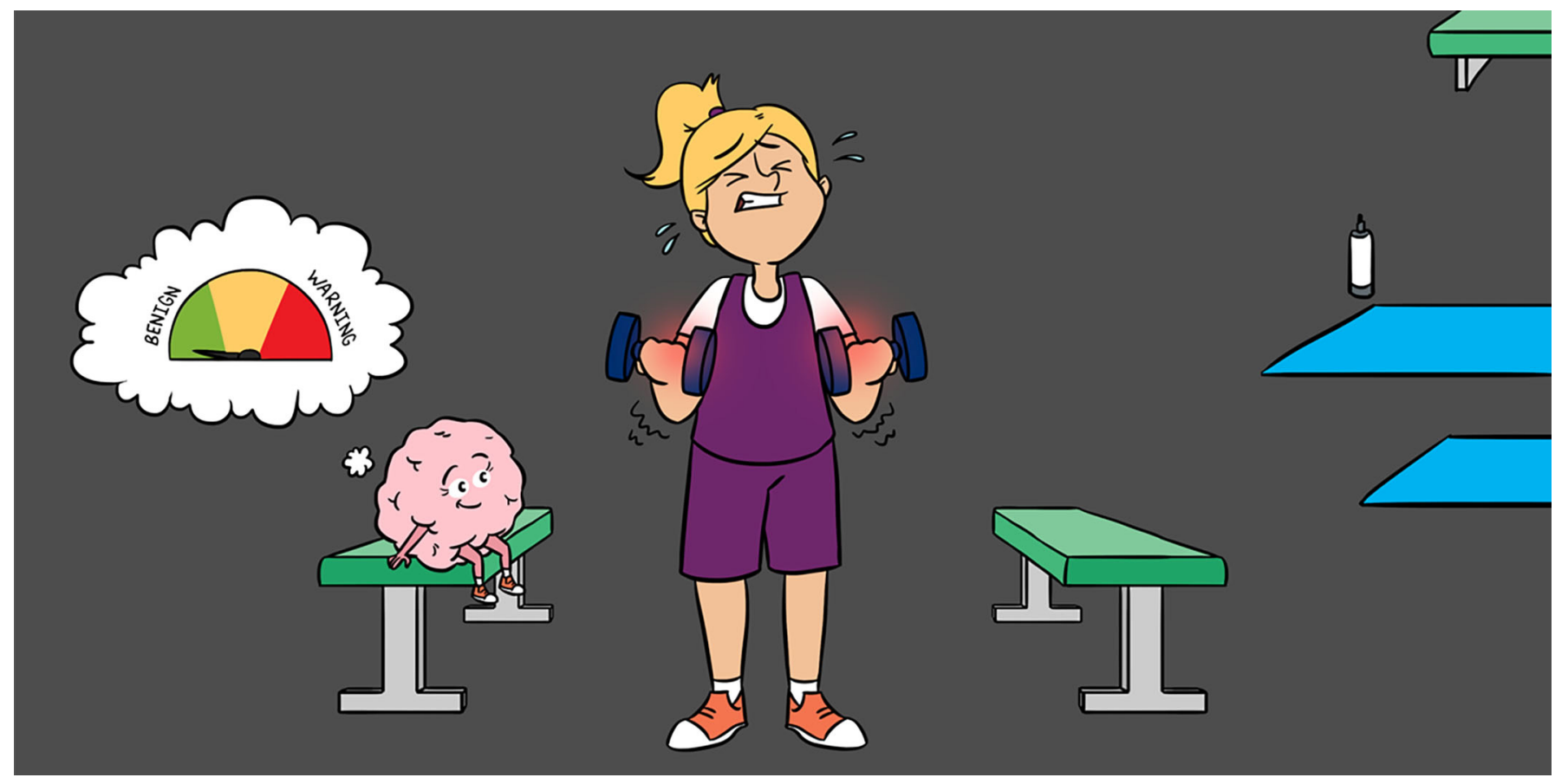

\title{
WORKING OUT YOUR PAIN: WHY INTENSE EXERCISE IS PAINFUL
}

\author{
Marcel Berger ${ }^{1}$, Daniel Henning ${ }^{2}$ and Michael C. Hout ${ }^{3,4^{*}}$ \\ ${ }^{1}$ Department of Kinesiology and Dance and Psychology, New Mexico State University, Las Cruces, NM, United States \\ ${ }^{2}$ Hearing Enhancement and Augmented Reality Laboratory, Department of Psychology, New Mexico State University, \\ Las Cruces, NM, United States \\ ${ }^{3}$ Vision Sciences and Memory Laboratory, Department of Psychology, New Mexico State University, Las Cruces, NM, \\ United States \\ ${ }^{4}$ Addison Care Virtual Reality and Augmented Reality Laboratory, New Mexico State University, Las Cruces, NM, United States
}

\section{YOUNG REVIEWERS:}

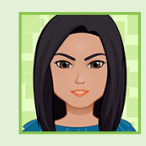

MRITTIKA

AGE: 13

SAANVI

AGE: 12
When it comes to experiencing pain, most people will agree that it is an uncomfortable sensation that we would rather avoid. Pain can vary in intensity-ranging from the mild sensation of stubbing your toe to the intense pain of a broken bone-and we generally think of it as a bad thing. But pain can be thought of in two ways: sometimes it is a warning signal that something is wrong with our bodies, but other times it is benign, meaning it is not an indication that something is necessarily wrong. Warning-signal pain occurs when certain areas of your body get hurt or experience tissue damage, like when a sibling accidentally closes the car door on your fingers. Benign pain, on the other hand, is the type of pain you feel during intense physical exercise, and as you will come to see, is not always something you need to avoid! 
Figure 1

(A) Non-myelinated C-fibers transmit dull pain, for example, the type of pain you feel when you are sunburned. (B) Myelinated A-fibers transmit sharp pain, such as the type of pain you feel when you cut your finger. Myelinated A-fibers conduct neural signals faster than C-fibers, due to their myelin sheaths. Myelin is a fatty-like substance that acts as an insulator for neurons, allowing signals to move quickly from the cell body to the axon terminals, where they communicate to other neurons.

\section{SENSATION}

The process of taking information in from the world around you by using the senses.

\section{PERCEPTION}

The process of making sense of a detected sensation.

\section{NOCICEPTOR}

A sensory receptor that responds to potentially damaging stimuli, sending a signal that results in the feeling of pain.
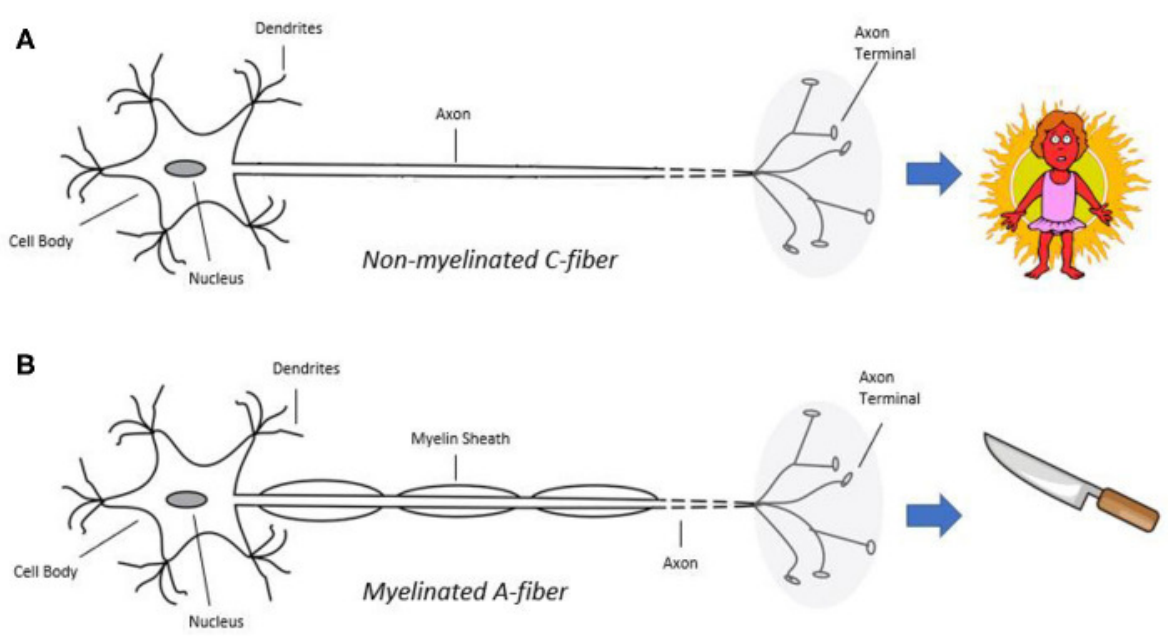

Figure 1

\section{HOW DO WE FEEL PAIN?}

Ordinarily, pain is experienced when your brain detects something that has the potential to damage your bodily tissues. Feeling pain starts with sensation and ends with perception. Sensation is when your body takes in information from the world around you; this could be light coming into your eyes, sound coming into your ears, or a physical feeling from something contacting your skin. Perception happens in the brain and is the process of making sense of sensation information or interpreting its meaning. For instance, your eyes sense light, but your brain interprets this information so you can understand (perceive) that you are looking at a pretty dog. Similarly, your skin may sense pressure, but it is your brain that perceives this information so that you can know that the dog just brushed up against your legs [1].

When we are hurt, the ability to determine whether the pain comes from an inner or outer source is dependent on specific sensory receptors within our bodies. These receptors detect specific types of stimuli, such as temperature, pressure, or chemical exposure. Receptors responsible for perceiving pain are called nociceptors. Nociceptors use two different types of fibers, called neurons, to communicate information from your body to your brain (Figure 1). Think of these fibers as the information highways that the nervous system uses to send signals. Type A fibers are myelinated, which means that the neuronal fibers are surrounded by a thin layer of fat called myelin. Myelin speeds up neural impulses just like an electrical wire that is surrounded by a rubber insulator, and this quick transmission communicates information about "sharp" pain, such as when you cut your finger. The other type of fiber, Type $C$, is unmyelinated. These fibers have less "insulation," so they carry signals more slowly [2]. The information these fibers carry is often described as "dull" pain, such as that of a sunburn. 
As humans get older, we tend to develop long-lasting diseases and painful syndromes. The neurons of older people tend to repair themselves more slowly and their functioning often decreases. However, that does not mean we must endure more pain later in life. Recent research has shown that exercise can improve our resilience against age-related diseases, increase balance, reduce risk of falls, and make us more capable of managing our pain [3]. Moreover, physical exercise supports brain functions, such as learning and mental performance [4]. All this evidence suggests that consistent exercise throughout life not only promotes quality of life at a later age, but it improves mental well-being and could even increase lifespan [5].

\section{STAGES AND TYPES OF PAIN}

Pain is a complex phenomenon and the pain you feel may be different than what other people feel-but everyone agrees that pain is unpleasant and preferably avoided! Because there is no direct way to measure someone else's pain, doctors often ask patients to rate their own pain on a scale from 0 to 10 , so that the doctor has some sense of the intensity of a patient's discomfort.

There are three basic stages that make up each person's unique experience to a painful stimulus. These stages are interrelated and involve different parts of the brain. All three stages taken together result in the overall experience of pain that you have. The first stage tells you about the intensity, location, quality, and duration of pain. For example, imagine trying to run a mile as fast as you can: you would likely notice a higher intensity of pain compared to casually walking the same distance. The second stage is characterized by perceiving pain as unpleasant or emotional. For instance, you may experience frustration (or even anger!) while running because it is a difficult and possibly unpleasant task. The third stage involves understanding the context in which pain occurs. For example, you may recognize that the pain from running is not harmful like the pain of cutting yourself, and therefore it is not something you should be terribly worried about [6].

\section{ACUTE PAIN}

Pain that occurs in the short term, for up to 3-6 months.

\section{CHRONIC PAIN}

An ongoing, long-lasting pain usually occurring longer than 6 months.
Another important thing to understand is that pain can be either acute or chronic. Acute pain is short in duration, lasting from a moment up to 3 months, whereas chronic pain is persistent and long-lasting, ranging from 3 to 6 months or more [7]. When you exercise, you typically experience acute and benign (harmless) pain, and it is under your control because if you stop, it usually goes away quickly. This is different from the pain that you might experience when you injure yourself. In injury situations, you might even have an entirely different emotional reaction to the event, because rather than feeling happiness from exercising vigorously, you may be sad that you twisted your ankle, for instance, and will need to walk on crutches for a while as you heal. 
Figure 2

Expected pain levels during a fast 1-mile run. The colors represent the severity of pain: green $=$ no pain, yellow $=$ moderate pain, red $=$ severe pain [8].

\section{ANAEROBIC}

GLYCOLYSIS

The process by which energy is generated in muscle tissues without the presence of oxygen. Lactate, hydrogen ions, and other chemicals are produced by anaerobic glycolysis.

\section{LACTATE}

A molecule produced as a product of anaerobic glycolysis.

\section{HYDROGEN IONS}

Chemicals released during anaerobic glycolysis through a process called hydrolysis. When the exercise intensity is very many hydrogen ions accumulate in the muscle cell, leading to a decrease in $\mathrm{pH}$-amount.

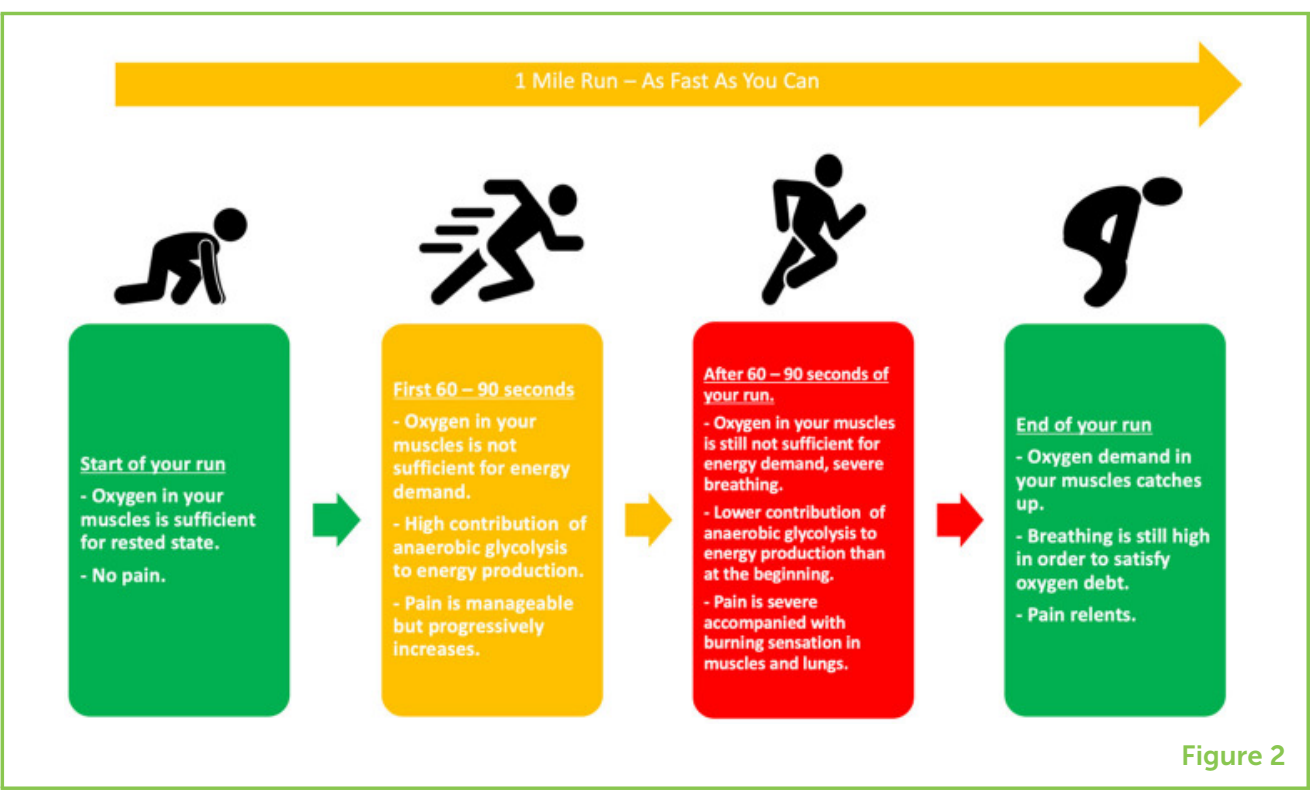

\section{WHY DO WE FEEL PAIN DURING EXERCISE?}

Because benign, exercise-induced pain is different from acute, harmful pain, it is important that we understand what is going on in our bodies when this type of pain occurs (See Figure 2). Imagine that you are trying to run one mile faster than you ever have before. That is a tough task, not only physically but also mentally! Even if you start at a pace you think you can maintain for the whole distance, during the first 60-90 s of the run your muscle cells will not have sufficient oxygen available to them. This is because the resting state you started from requires less oxygen than running. Because they do not have enough oxygen early in the run, your working muscles will generate energy using a process called anaerobic glycolysis. This process generates a product called lactate, as well as hydrogen ions and other chemicals. Running very fast with a highly activated anaerobic glycolysis decreases the $\mathrm{pH}$ of your muscle cells, making them slightly more acidic [2]. Essentially, you are creating a hostile environment within each of your working muscles, which then stimulates nociceptors that send signals to your brain, telling you that you are experiencing something painful.

As we mentioned earlier, pain perception has three distinct components that form your overall experience. The second (your emotional reaction) and third (how you evaluate the pain) stages are critical when you are trying to run your fastest mile. How we choose to feel and think about the experience will have a big impact on how much pain we feel. For example, when young children fall, they usually look around to see how other people react to the event. If a parent looks scared or worried, the child may take this as a signal that something bad has happened, and so they might feel scared or even cry. But if the parent appears unconcerned, the child will often brush off the experience altogether [9]. 
Similarly, the pain you experience during intense physical exercise may be lessened by practicing strategies, such as concentrating on the motions you need to perform and not on the pain, by focusing your attention on your goal of running your fastest mile, or by telling yourself that this pain is benign and will soon pass. For instance, the next time you are running a mile, try to focus on objects in the environment, such as distance markers on the track, or the movements of other athletes in your surroundings. You could also focus on a repetitive sequence of words or on some music. It does not have to be complicated; the important thing is that by focusing your attention away from the pain, you may be able to enjoy your exercise more and have a much more pleasant experience $[9,10]$.

\section{CONCLUSION}

The sensation and perception of pain are necessary for us to protect our bodies from damage, but it is important to remember that some pain tells the brain that damage is being done and other pain tells us simply that our muscles are working hard. Pain is a complex experience, and there is no magic pill to make it go away. We must simply remember that a little bit of benign pain during exercise is okay (provided we have not injured ourselves), and that, with a little mental effort, we can focus our attention elsewhere and learn to enjoy our exercise even more.

\section{REFERENCES}

1. Wolfe, J. M., Bartoshuk, L. M., Dennis, L. M., Herz, R. S., Kluender, K. R., Lederman, S. J., et al. 2015. Sensation and Perception, 4th Edn. Sunderland, MA: Sinauer Associates.

2. Marieb, E. N., and Hoehn, K. 2016. Human Anatomy \& Physiology. Boston, MA: Pearson.

3. Kaye, A. D., Baluch, A., and Scott, J. T. 2010. Pain management in the elderly population: a review. Ochsner J. 10:179-187.

4. Cotman, C. W., and Berchtold, N. C. 2002. Exercise: a behavioral intervention to enhance brain health and plasticity. Trends Neurosci. 25:295-301. doi: 10.1016/s0166-2236(02)02143-4

5. Papaioannou, A., Adachi, J. D., Winegard, K., Ferko, N., Parkinson, W., Cook, R. J., et al. 2003. Efficacy of home-based exercise for improving quality of life among elderly women with symptomatic osteoporosis-related vertebral fractures. Osteoporos. Int. 14:677-682. doi: 10.1007/s00198-003-1423-2

6. Melzack, R., and Casey, K. L. 1968. Sensory, motivational, and central control determinants of pain: a new conceptual model. Skin Senses 1:423-43.

7. Carr, D. B., and Goudas, L. C. 1999. Acute pain. Lancet 353:2051-8.

8. McArdle, W. D., Katch, F. I., and Katch, V. L. 2015. Exercise Physiology: Nutrition, Energy, and Human Performance, 8th Edn. Philadelphia, PA: Wolters Kluwer/Lippincott Williams \& Wilkins. 
9. Perry, J. 2016. Sport Psychology: A Complete Introduction. Hodder \& Stoughton General Division (London, UK).

10. Weinberg, R. S., and Gould, D. 2015. Foundations of Sport and Exercise Psychology. Champaign, IL: Human Kinetics.

SUBMITTED: 27 May 2020; ACCEPTED: 05 February 2021;

PUBLISHED ONLINE: 15 March 2021.

EDITED BY: Chandrasekaran Jayaraman, Shirley Ryan AbilityLab, United States

CITATION: Berger M, Henning D and Hout MC (2021) Working Out Your Pain: Why Intense Exercise Is Painful. Front. Young Minds 9:566420. doi: 10.3389/frym.2021. 566420

CONFLICT OF INTEREST: The authors declare that the research was conducted in the absence of any commercial or financial relationships that could be construed as a potential conflict of interest.

COPYRIGHT () 2021 Berger, Henning and Hout. This is an open-access article distributed under the terms of the Creative Commons Attribution License (CC BY). The use, distribution or reproduction in other forums is permitted, provided the original author(s) and the copyright owner(s) are credited and that the original publication in this journal is cited, in accordance with accepted academic practice. No use, distribution or reproduction is permitted which does not comply with these terms.

\section{YOUNG REVIEWERS}

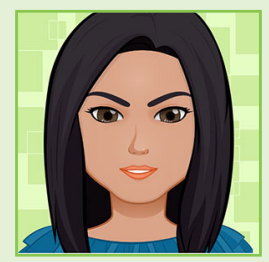

\section{MRITTIKA, AGE: 13}

Mrittika loves hanging out with friends and family. Her interests include: playing the viola and ukulele, dancing, poetry, singing, reading, and calligraphy. Math, Social Studies, and Music are her favorite subjects and she enjoys volleyball, karate, and running. Mrittika's favorite accomplishments are becoming a senior editor in her yearbook editing team and being in her school's show choir. She is also her school's geography bee champion and a finalist in a nationwide computer science competition. Mrittika aspires to be a more open-minded and knowledgeable person.

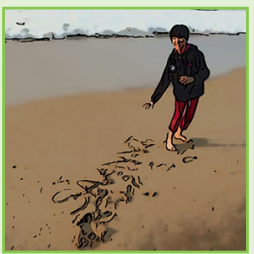

\section{SAANVI, AGE: 12}

Hello, I am Saanvi, a 12 year girl from India. I like reading, cats, and beaches. I love to write my name in wet sands!

\section{AUTHORS}

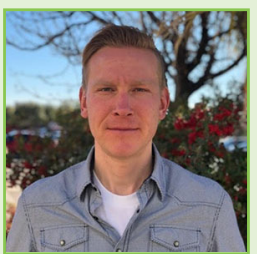

\section{MARCEL BERGER}

Marcel studied Kinesiology and Psychology at New Mexico State University. Currently, Marcel studies Applied Sport Psychology at the Martin Luther University Halle-Wittenberg. He is interested in research on Exercise Science, Sports Medicine, 

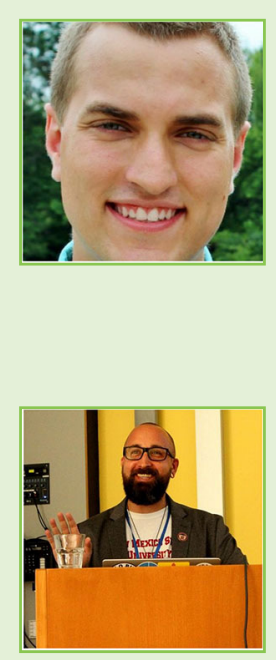

Sport Psychology, and Psychology. Marcel is involved in the realm of performance cycling as a cycling coach and athlete.

\section{DANIEL HENNING}

I am a doctoral student in engineering psychology at New Mexico State University, and I am interested in three-dimensional audio and virtual/augmented reality. I am interested in applying what I learn to create a better audio environment for an immersive experience in a virtual setting. To do this, I am learning to implement machine learning techniques to have a computer program "learn" and help create more accurate audio representations.

\section{MICHAEL C. HOUT}

I am an Associate Professor in the Psychology Department at New Mexico State University, and an Associate Editor at the journal Attention, Perception, \& Psychophysics. My research examines many different things, but I primarily study visual search (how people find things) and eye movements (where and why we move our eyes). In my limited spare time, I like to play with my dogs, go on motorcycle rides, hike, travel, and play hockey. *mhout@nmsu.edu 